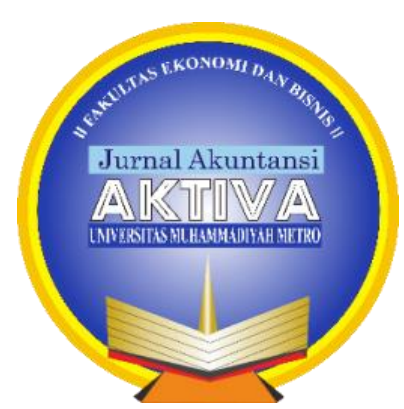

Jurnal Akuntansi AKTIVA, Vol 1, No. 2 Oktober 2020

\title{
ANALISIS SISTEM PENERIMAAN DAN PENGELUARAN KAS PADA RSU MUHAMMADIYAH METRO
}

\author{
${ }^{1}$ Nawang Intan Sari, ${ }^{2}$ Nedi Hendri, ${ }^{3}$ Sri Retnaning Rahayu \\ 1,2,3 Universitas Muhammadiyah Metro, Jl. Ki Hajar Dewantara, 34111, Lampung, Indonesia \\ E-mail : nawangintansari9@gmail.com, nedi_hendri@yahoo.com, retnaning27@gmail.com,
}

\begin{abstract}
ABSTRAK
Penelitian tujuan mengetahui sistem penerimaan dan pengeluaran kas pada RSU Muhammadiyah Metro. (1) Sistem Informasi Manajemen (SIM), yang terjadi di RSU Muhammadiyah Metro. Desain penelitian yang digunakan peneliti dalam penelitian ini menggunakan pendekatan kualitatif. Objek penelitian ini adalah Objek dalam penelitian ini adalah penerimaan dan pengeluaran kas, dan sistem SIM RS, dalam penelitian tersebut penulis ditempatkan di bagian keuangan. Teknik pengambilan sampel yang digunakan adalah dokumentasi. Penelitian ini menggunakan pendekatan kualitatif. Hasil penelitian menunjukkan penerimaan dan pengeluaran kas, dan sistem SIMRS kurang efektif untuk digunakan.
\end{abstract}

Kata Kunci : Sistem, Penerimaan, Pengeluaran Kas

\begin{abstract}
This study aims to determine the system of cash receipts and disbursements at Muhammadiyah Metro Hospital. (1) Management Information System (SIM), which occurs at Muhammadiyah Metro Hospital. The research design used by researchers in this study used a qualitative approach. The object of this research is the object of this research is cash receipts and disbursements, and the SIM RS system, in this study the author is placed in the finance department. The sampling technique used is documentation. This research uses a qualitative approach. The results showed cash receipts and disbursements and the SIMRS system were less effective to use.
\end{abstract}

Key Words : System, Receipts, Cash Disbursements. 


\section{PENDAHULUAN}

\section{Latar Belakang Masalah}

Rumah sakit merupakan perusahaan yang berbentuk jasa yang bertujuan memberikan pelayanan kesehatan. Pada umumnya penerapan sistem rumah sakit sangat penting bagi rumah sakit, terutama sistem penerimaan dan pengeluaran kas. Hal ini dikarenakan penerimaan dan pengeluaran kas tersebut sangat mudah disalahgunakan oleh pihak-pihak yang tidak bertanggung jawab. Oleh karena itu, diperlukan sebuah penerapan sistem akuntansi penerimaan dan pengeluaran kas yang tepat, agar terjaga kas rumah sakit dari penyalahgunaan yang mungkin terjadi di rumah sakit. Rumah Sakit Umum (RSU) Muhammadiyah Metro telah dimulai sejak tahun 1967. Pada tahun itu, Pimpinan Cabang Muhammadiyah Kabupaten Lampung Tengah di Metro telah memiliki izin operasional Rumah Sakit Penolong Kesengsaraan Oemat (RS-PKO) Muhammadiyah dari LKES Provinsi Lampung yang ditandatangani oleh Dr. Enjun sebagai Kepala LKES Provinsi Lampung.

Namun, pada perkembangan selanjutnya Pimpinan Muhammadiyah Cabang Kabupaten Lampung Tengah lebih terkonsentrasi pada upaya ppenyelamatan Universitas Muhammadiyah Jakarta Cabang Lampung di Metro sehingga upaya-upaya pengembangan RS PKO Muhammadiyah menjadi tidak maksimal. Pada bulan Agustus 1982, Pimpinan Muhammadiyah Cabang Lampung Tengah berkembang menjadi Pimpinan Muhammadiyah Daerah (PMD) Lampung Tengah dengan Metro sebagai pusat gerakannya. Berkat kegigihan dan keuletan dari berbagai pihak saat ini RSU Muhammadiyah Metro kini telah siap melayani pasien sejak bulan Oktober 2007 dan diresmikan pada tanggal 22 Januari 2008. Tidak hanya melayani persalinan, sejak itu Rumah Sakit Muhammadiyah Metro menjadi Rumah Sakit yang juga melayani pasien umum.

\section{Rumusan Masalah}

Berdasarkan latar belakang masalah yang telah dipaparkan diatas, maka penelitian ingin mngetahui tentang

1. Bagaimana Sistem Penerimaan dan Pengeluaran Kas pada RSU Muhammadiyah Metro ?

2. Apakah Sistem SIM RS apakah sudah efektif untuk digunakan pada RSU Muhammadiyah Metro ? 


\section{Tujuan Penelitian}

Berdasarkan identifikasi masalah yang telah dipaparkan di atas, maka penelitian ini bertujuan :

1. Untuk mengetahui Sistem Penerimaan dan Pengeluaran Kas pada RSU Muhammadiyah Metro ?

2. Untuk mengetahui Sistem SIM RS apakah sudah efektif untuk digunakan pada RSU Muhammadiyah Metro?

\section{KAJIAN LITERATUR \\ Kajian Objek}

Rumah sakit adalah bagian integral dari suatu organisasi sosial dan kesehatan dengan fungsi menyediakan pelayanan paripurna (komprehensif), penyembuhan penyakit (kuratif) dan pencegahan penyakit (preventif) kepada masayarakat. Rumah sakit juga merupakan pusat pelatihan bagi tenaga kesehatan dan pusat penelitian medik.Sedangkan menurut undang-undang RI No. 44 Tahun 2010 tentang rumah sakit, fungsi rumah sakit yaitu "Pemeliharaan dan peningkatan kesehatan perorangan melalui pelayanan kesehatan yang paripurna tingkat kedua da ketiga sesuai kebutuhan medis".

\section{Sistem Akuntansi Kas}

Pengertian sistem kas adalah suatu paduan yang terdiri dari beberapa unsur yang tergabung satu sama lain agar mempermudah laju aliran informasi, energi ataupun materi hingga dapat mencapai tujuan tertentu. Sistem menurut Zaki Baridwan sebagai berikut "suatu kerangka dari prosedur-prosedur yang saling berhubungan yang disusun sesuai dengan suatu skema yang menyeluruh, untuk melaksanakan suatu kegiatan atau fungsi utama dari perusahaan" (1998: 3)

\section{Sistem Akuntansi Pengeluaran Kas}

Sistem Akuntansi Pokok yang digunakan untuk melaksanakan Pengeluaran Kas adalah Sistem Akuntansi Pengeluaran dengan menggunakan transfer dan Sistem Pengeluaran Kas dengan menggunakan uang tunai melalui Dana Kas Kecil (Mulyadi,2001:509). 


\section{Sistem Informasi Manajemen}

SIM adalah perangkat prosedur yang terorganisasi apabila dijalankan akan memberikan umpan balik dan informasi kepada manajemen tetang masukan, proses, dan keluaran dari suatu siklus manajemen, yaitu perencanaan, pelaksanaan, evaluasi dan pengendalian.

\section{METODE PENELITIAN}

\section{Jenis Penelitian}

Jenis penelitian dalam pengambilan data pada yang berhubungan dengan permasalahan yang terdapat pada penulisan ilmiah ini menggunakan du acara :

1. Penelitian kepustakaan penelitian yang di lakukan dengan mengumpulkan data dan informasi berbagai literature dan tulisan ilmiah dari berbagai sumber yang dapat dipergunakan landasan teori dalam penulisan Tugas Akhir ini.

2. Penulisan lapangan penelitian yang di lakukan dengan mengadakan hubungan langsung dengan responden, yaitu dengan wawancaara.

\section{Metode Penelitian}

Metode penelitian yang digunakan oleh penulis adalah kualitatif, yaitu prosedur penelitian yang menghasilkan suatu data deskriptif berupa kata-kata tulisan dari fenomena yang diamati di lapangan oleh peneliti. Penelitian ini besifat deskriptif kualitatif dan flowchart yaitu penelitian yang menggambarkan data informasi yang berdasarkan pada fakta yang diperoleh di lapangan.

\section{Objek dan Lokasi Penelitian}

Objek dalam penelitian ini adalah penerimaan dan pengeluaran kas, dan sistem SIM RS, dalam penelitian tersebut penulis ditempatkan di bagian keuangan. Penelitian ini di lakukan di RSU Muhammadiyah Metro yang terletak di Jl. Soekarno Hatta No. 42 MulyoJati 16 B Metro Barat, Lampung.

\section{Teknik Pengumpulan Data}

Penelitian lapangan adalah dipergunakan untuk mendapatkan data primer langsung dari objek penelitian Data primer adalah data yang langsung diperoleh dari sumber data. 


\begin{abstract}
Alat Analisis Data
Mengkategorikan Informasi atau data mengenai prosedur penerimaan dan pengeluaran kas akan disajikan dalam bentuk deskriptif kualitatif dan flowchart. Pengendalian aplikasi SIMRS akan jauh lebih efektif jika didukung oleh adanya pengendalian umum yang kuat terhadap sistem tersebut. Jika pengendalian aplikasi lemah, output SIA akan mengandung kesalahan.
\end{abstract}

\title{
HASIL DAN PEMBAHASAN
}

Deskripsi kegiatan dalam sistem akuntansi penerimaan kas dari pembayaran rawat inap. Pelayanan rawat inap oleh fungsi perawat dengan melayani pasien, setelah itu pasien melakukan pembayaran atas kegiatan rawat inap ke fungsi kasir.

Pasien berobat melalui IGD, kemudian pasien mendaftar ke fungsi pendaftaran, setelah itu mengisi formulir pendaftaran, setelah itu pasien memilih ruangan kelas terlebih dahulu, kemudian itu fungsi pendaftaran menghubungi fungsi keperawatan, dan formulir pendaftaran diserahkan ke fungsi perincian. Kemudian fungsi keperawatan menyiapkan ruangan kelas yang telah dipilih pasien, kemudian pasien diberi tindakan dokter dan tindakan keperawatan dan dicatat ke status rekam medis, setelah itu fungsi keperawatan menyerahkan status rekam medis ke fungsi perincian, setelah itu fungsi perincian merekap biaya pasien dari status rekam medis dan di input ke NCI kedalam data perincian pasien 2 lembar. Setelah itu kwitansi 2 lembar dan perincian pasien 2 lembar diserahkan ke fungsi kasir. Kendala SIMRS Pada RSU Muhammadiyah Metro

1. Sistem SIMRS Kurangnya penyajian data yang beberapa supplier tidak ada disistem tersebut.

2. Terhambatnya informasi, dikarenakan dalam sistem SIMRS terjadi tidak efektif.

3. Sistem SIMRS ini terkadang terjadi eror karena saat melakukan penginputan.

\section{KESIMPULAN DAN SARAN}

\section{Kesimpulan}

Hasil dari penelitian dan pembahasan yang dilakukan yang dilakukan pada RSU Muhammadiyah, serta ditunjang dengan teori-teori yang dijelaskan pada bab sebelumnya, maka penelitian dapat menarik simpulan sebagai berikut :

1. Penerapan sistem penerimaan dan pengeluaran kas di RSU Muhammadiyah sudah baik, sesuai dengan prosedur pada umumnya dan telah mencerminkan pengendalian Intern yang baik. 
2. Sistem penerimaan kas dari pembayaran rawat inap, sistem penerimaan kas dari instalsi gawat darurat, karena sesuai dengan prosedur yang di jalankan.

3. Secara keseluruhan RSU Muhammadiyah telah memenuhi unsur-unsur sistem informasi penerimaan dan pengeluaran kas. Kendala hanya terjadi pada sistem SIMRS kurang efektif saat penagihan .

4. Keunggulan SIMRS pada RSU Muhammadiyah pada tahun 2020 dapat diakatakan kurang baik. Hal ini ditunjukan dari masalah SIMRS beberapa nama supplier tidak muncul disistem tersebut. Adapun permasalahan yaitu, penyajian data, dan terhambatnya informasi.

\section{Saran}

Adapun saran yang diberikan setelah melakukan penelitian ini adalah :

1. Meskipun prosedur penerimaan dan pengeluaran kas di RSU Muhammadiyah sudah baik, sesuai dengan prosedur pada umumnya dan telah mencerminkan pengendalian Intern yang baik. Namun perlu lebih diperhatikan lagi dalam dalam penginputan, dan tidak terjadi resiko yang besar dikemudian hari.

2. Bagi Rumah Sakit, sebaiknya memperbaiki sistem SIMRS agar bisa nama-nama supplier ada semua disistem tersebut dan lebih memudahkan saat penagihan.

3. Besar harapan saya semoga apa yang kami usulkan dapat membantu kegiatan operasional di rumah sakit sehingga akan terjadi bentuk nyata terhadap peningkatan SIMRS kepada supplier rumah sakit.

4. Bagi peneliti selanjutnya disarankan agar dapat meneliti penerimaan dan pengeluaran kas secara SIMRS, karena pada peneliti ini hanya meneliti sistem penerimaan dan pengeluaran serta SIMRS saja, sehingga hasil peneliti selanjutnya akan semakin baik.

\section{DAFTAR PUSTAKA}

Mulyadi (2001). Sistem Akuntansi. Edisi Tiga. Jakarta, Salemba Empat

Bahari, I.S., Dwiatmanto, dan Endang, M.G.W. (2017). Analisis sistem akuntansi penjualan dan penerimaan kas dalam upaya pengendalian intern. Jurnal Administrasi Bisnis (JAB), Vol. 53 No. 1 Desember 2017.

Baridwan, Z. (2013). Sistem informasi akuntansi, Ed. Ke-dua, Cet. Ke-delapan. Yogyakarta:BPEEYogyakarta.

Diana, A., dan Setiawati, L. (2011). Sistem informasi akuntansi. Yogyakarta : Adi Offset.

Hall, J.A.(2007).Sistem informasi akuntansi. Jakarta : Salemba Empat. 
Maria, D.I. dan Mustikowati, R.I. (2016). Analisis sistem informasi akuntansi (SIA) pendapatan rawat inap.

A.Hall, James. 2001. Sistem Informasi Akuntansi. Thomsom Learning.

Krismaji. (2005). Sistem informasi akuntansi. Ed. Ke-dua. Yogyakarta:Unit Penerbit dan Percetakan Akademic Manajemen Perusahaan YKPN.

Mulyadi. (2016). Sistem Akuntansi. Ed. Ke-empat. Jakarta: Salemba Empat.

Widjajanto,N. (2001). Sistem informasi akuntansi. Jakarta:Erlangga.

Saifudin dan Ardani, F.P. (2017). Sistem informasi akuntansi penerimaan dn pengeluaran kas dalam meningkatkan pengendalian internal atas pendapatan pada RSU Dr. Kariadi Semarang Jurnal Riset Akuntasi Keuangan Volume 2 No. 2 April 2017.

Maria, D.I. dan Mustikowati, R.I. (2016). Analisis sistem informasi akuntansi (SIA) pendapatan rawat ina kamar VIP RSUD Kota Lawang. Jurnal Riset Mahasiswa Akuntansi (JRMA). 